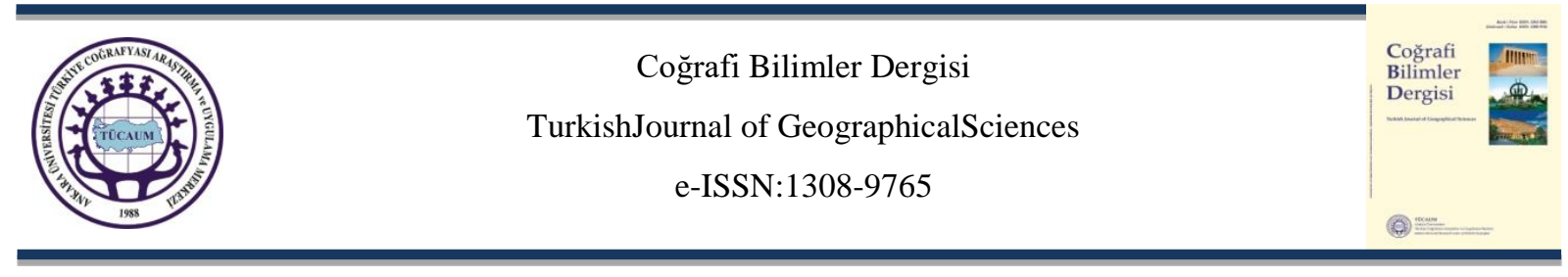

\title{
Banaz'da (Uşak) Yeni Bulunan Petrifiye Alanı ile İlgili İlk Bulgular ${ }^{*}$
}

\author{
The first findings on fossil trees area located in Banaz (Uşak) \\ Selahattin Polat ${ }^{\mathrm{a}}$, Yıldız Güney*b, İsmail Ege ${ }^{\mathrm{c}}$, Ünal Akkemik ${ }^{\mathrm{d}}$
}

\begin{tabular}{l} 
MakaleBilgisi \\
\hline DOI: \\
10.33688/ aucbd.532176 \\
\hline MakaleGeçmişi: \\
Geliş: 25.02 .2019 \\
Kabul: 06.09.2019 \\
\hline AnahtarKelimeler: \\
Fosil Ağaç \\
Taşlaşmı̧̧ Ağaç \\
Sekoya Grubu \\
Paleobotanik \\
Banaz
\end{tabular}

\begin{tabular}{l} 
Article Info \\
\hline DOI: \\
10.33688/ aucbd.532176 \\
\hline Article History: \\
Received: 25.02 .2019 \\
Accepted: 06.09.2019 \\
\hline Keywords: \\
Fossil Tree \\
Petrified Wood \\
Sequoiaxylon \\
Paleobotanic \\
Banaz
\end{tabular}

\begin{abstract}
$\ddot{O} z$
Doğa tarihi, paleocoğrafya ve paleoklimatoji açısından önemli olan fosil ormanlara Türkiye'den yeni bir katkı olarak yeni bir fosil orman alanı, Uşak ili Banaz ilçesi batısında, Karatepe, Alan Tepe, Söpseke Sirtı, Sakızocak Tepe, Tuzlagedik Tepe arasında kalan alanda tespit edilmiştir. Bu alanda, 2-60 metre kalınlığındaki Paleojen'e ait silisli lateritik depolar içinde silisleşmiş ağaç fosilleri bulunmaktadır. Geniş bir alana yayılmış durumda bulunan silisleşmiş ă̆aç fosillerinin boyutları 1,5 m uzunluğuna ve $70 \mathrm{~cm}$ çapına kadar ulaşmaktadır. Çalışmanın amacı, bu silisleşmiş ăgaçların tanısını yapmak, fosil orman özelliğini belirlemek ve paleocoğrafik açıdan değerlendirmektir. Araştırma alanından alınan örneklerden makroskobik olarak farklılık gösterdiği değgerlendirilen 4 örnekten enine, radyal ve teğet kesitleri alınarak tanı çalışmaları yapılmıştır. Yapılan analizler sonucunda silisleşmiş ă̆açların sekoya grubu (Sequoioxylon) olduğu sonucuna varılmıştır. Günümüzde ülkemizde doğal olarak yayılışı bulunmayan Sequoia tipi ăgaçların varlı̆̆ bu alanda Paleojen boyunca ılıman iklim koşullarının hakim olduğu bataklık orman ya da dere kenarı vejetasyonunun bulunduğunu göstermektedir.
\end{abstract}

\begin{abstract}
Fossil forests are one of the important areas in terms of natural history, paleogeography and paleoclimatology. A new fossil forest was discovered in the area between the Tuzlagedik Tepe and the Sakizocak Tepe, Karatepe, the Alan Tepe, west of the Banaz district of Uşak province. In this area, silicified lateritic formations of Paleogene belonging to 2-60 meters thick are found in silicified tree fossils. The size of silicified tree fossils spread over a wide area reaches up to $1.5 \mathrm{~m}$ in length and $70 \mathrm{~cm}$ in diameter. The aim of this study is to diagnose these silicified trees, to determine the fossil forest characteristics and to evaluate paleogeography. Transverse, radial and tangent sections were taken from 4 samples which were examined macroscopically. As a result of the analysis it was concluded that silicified trees are Sequoioxylon. The presence of Sequoia trees, which don't naturally spread in our country today, indicates that there is a marsh forest or riperian vegetation where temperate climatic conditions prevail during the Paleogene.
\end{abstract}

\footnotetext{
*Bu makale 03.10.2018-06.10.2018 tarihlerinde gerçekleşen TÜCAUM 30. Yıl Uluslararası Coğrafya Sempozyumu'nda sözlü bildiri olarak sunulmuştur. Özet veya tam metin bildiri olarak yayınlanmamıştır.

*Sorumlu Yazar/Corresponding Author: Yıldız Güney, yildiz.guney@ gmail.com

aUşak Üniversitesi, Fen-Edebiyat Fakültesi, Coğrafya Bölümü, Uşak, Türkiye, http://orcid.org/0000-0002-8042-1918

bUşak Üniversitesi, Fen-Edebiyat Fakültesi, Coğrafya Bölümü, Uşak, Türkiye, http://orcid.org/0000-0002-0756-9246

${ }^{c}$ Uşak Üniversitesi, Fen-Edebiyat Fakültesi, Coğrafya Bölümü, Uşak, Türkiye, http://orcid.org/0000-0001-5896-0440

dİstanbul Üniversitesi-Cerrahpaşa, Orman Fak., Orman Müh. Böl., İstanbul, Türkiye, http://orcid.org/0000-0003-2099-5589
} 


\section{Giriş}

Silisleşmiş ağaçlar ve bu ağaçlardan oluşan fosil ormanlar, doğa tarihini, paleoklimatolojik ve paleocoğrafik değişimleri anlamak için önemli miras alanlarıdır. Bu yönleriyle birer doğa mirası niteliğinde olan fosil ormanlar ülkemizde de bulunmaktadır. Ülkemizdeki fosil ormanlarda bulunan silisleşmiş ağaçlar üzerine yapılan çalışmalar son yıllarda giderek yaygınlaşmaktadır. İlk çalışmalar Özgüven-Ertan (1971, 1977 ve 1981(1983)) tarafindan yapıldıktan sonra Eroskay ve Aytuğ (1982) ile devam etmiş ve günümüzde hızlı bir artış göstermiştir. Türkiye'de Oligosen'den Pliyosen'e farklı jeolojik çağlardan günümüze ulaşan fosil ormanlarla ilişkili literatürde Doğu Trakya Ergene Havzası (Akkemik vd., 2005), Çamlıdere - Pelitçik köyü (Akkemik vd., 2009), Seben - Hoçaş köyü (Akkemik vd., 2016), Güdül (Akkemik vd., 2017), Haymana (Akkemik vd., 2018), Galatya Masifi (Bayam vd., 2018), Gökçeada (Güngör vd., 2019) İstanbul'un kuzeyi (Akkemik vd., 2019) ve Kütahya çevresinde (Akkemik vd., 2019) çalışmalar yapılmıştır.

Fosil ormanı oluşturan silisleşmiş ağaçlardan özellikle Ankara-Bolu hattındakiler dikili ve yatık halde (taşınmış) durumda (Bayam vd., 2018) iken diğer alanlardakilerden tamamı irili ufaklı taşınmış materyaller halindedir. Bunlara genel olarak bütün halinde rastlamak güç iken, özellikle Ankara-BoluKütahya-Eskişehir çevrelerinde (Akkemik vd., 2017, 2018; Akkemik, 2019; Bayam vd., 2018) ve Trakya'da yer yer fosil ağaç kalıntıları (Akkemik vd., 2019) şeklinde ulaşmak mümkündür. Bunlar genellikle taşınmış materyaller halindedir.

Türkiye'de makrofosiller (Denk vd., 2017 a,b,c; Gemici vd., 1991; Kasaplıgil, 1971), silisleşmiş ağaçlar (Akkemik vd., 2005, 2009, 2016, 2017, 2018, 2019; Akkemik, 2019; Akkemik ve Sakınç, 2012; Akkemik vd., 2009; Bayam vd., 2018; Dernbach vd., 1996; Eroskay ve Aytuğ, 1982; Güngör vd., 2019; Özgüven, 1971, 1977, 1981(1983); Sayadi, 1973; Selmeier, 1990; Şanl1, 1982; Türkoğlu vd., 2009'dan aktarım) ve mikrofosillere (Bat1, 1996; Karlığlu vd., 2009; Kayseri ve Akgül, 2007; Şanl1, 1982) dayalı araştırmalar son yıllarda artmaya başladığından Geç Oligosen'den Pliyosen'e önemli paleocoğrafya bulgulara da ulaşılmaktadır. Bu çalışmalar, önemli bir gelişme olmakla birlikte henüz daha başlangıç aşamasındadır.

Çalışmanın amacı, varlığı ilk defa tarafımızca tespit edilen Yukarı Karacahisar (Banaz) silisleşmiş fosil ağaçlar hakkında ilk bulguları paylaşmaktır. Fosiller, Türkiye'deki diğer bölgelerde bulunan fosil ağaçlardan, yoğun ve oldukça kalın silisleşmiş ağaç gövdelerinin varlığı ile farklılık göstermektedir. Ege Bölgesi'nde, bilinen diğer fosil ağaçlar Osmancalı (Manisa) köyünde bulunmaktadır (Yurtseven, 2018). Bu fosil ağaçlar, bulunduğu jeolojik zamanın paleocoğrafyasını ve paleoekolojisini ortaya koymak açısından önemli olduğu gibi, Anadolu'nun geçirmiş olduğu evrimin açıklanması bakımından da önemli veriler sunmaktadır. Nitekim bu silisleşmiş ağaç fosilleri geçmişin kaydını bünyesinde tutmaktadır. Bu çalışmadaki temel amaç bunların literatüre kazandırılmasıdır.

\subsection{Petrifiye Alanının Konumu ve Genel Fiziki Coğrafya Özellikleri}

Yukarı Karacahisar fosil ağaçları Uşak il merkezinin kuzeydoğusunda, karayolu ile $40 \mathrm{~km}$ uzaklıktadır. Alan idari olarak Banaz ilçesi, Yukarı Karacahisar köyü sınırları içinde ve yerleşmenin

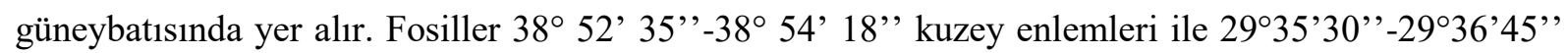
doğu boylamları arasında bulunmaktadır. Yaklaşık $3.1 \mathrm{~km}^{2}$ 'lik alana fosiller dağılmış durumdadır. Fosil 
alanı doğudan Küçükler Barajı kuşatır. Kuzeyde Mestalanı Dere, güneyde ise Kara Dere arasında kalan alanda Alanyaka ve Tazılan Burnu mevkiinde fosiller yoğunlaşmaktadır (Şekil 1, Foto 1).

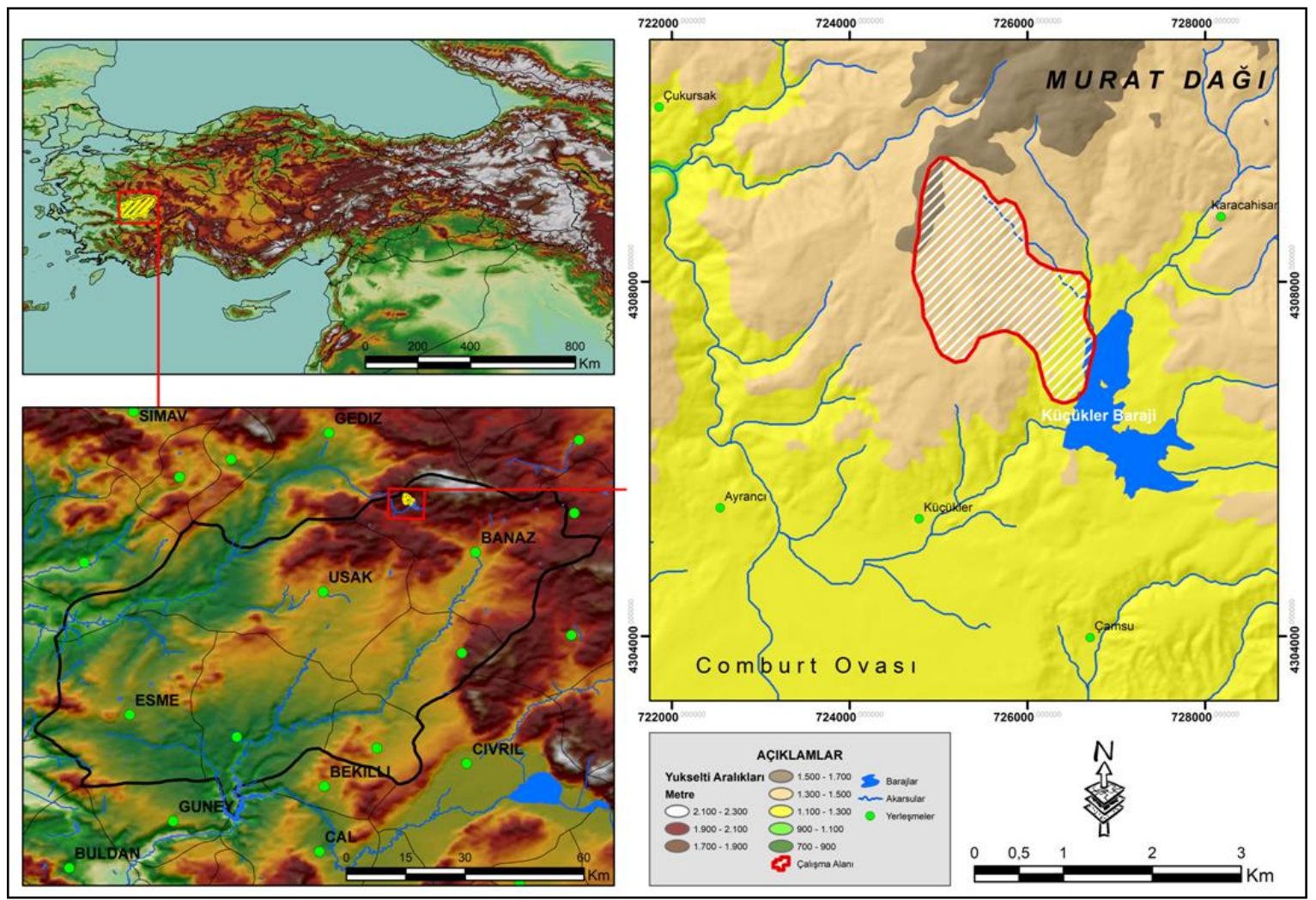

Şekil 1. Araştırma alanın lokasyon haritası.

Uşak ve Gediz Meteoroloji İstasyonları verilerine göre yıllık ortalama sıcaklık $12{ }^{\circ} \mathrm{C}$ civarında iken, Murat Dağı'nın zirve kesimlerinde sıcaklık $3{ }^{\circ} \mathrm{C}$ 'ye kadar düşer. Araştırma sahası ve çevresinde ise yıllık ortalama sıcaklık $9{ }^{\circ} \mathrm{C}$ civarındadır. Yıllık yağış miktarı ise belirtilen istasyonlardan Uşak'da 540 mm, Gediz'de ise 603 mm'dir. Bu miktar çalışma alanında 800-900 mm'yi bulur.

Murat Dağı, Avrupa-Sibirya, Akdeniz ve İran-Turan fitocoğrafya bölgesine ait bitkilerin bulunduğu konuma sahiptir. Silisleşmiş ağaçlar, Murat Dağı'nın güneyinde kuru ormanın yayılış gösterdiği alanda bulunur. Günümüzde alanın hâkim bitki türünü karaçam (Pinus nigra Arnold subsp. pallasiana) oluşturur. Bunun yanında ardıç (Juniperus sp.), geyik dikeni (Crataegus sp.) gibi bitkiler de dikkati çeker. Karaçamların tahrip edildiği yerlerde küçük topluluklar halinde titrek kavaklar (Populus tremula) ve ladenler (Cistus laurifolius.) gelişme göstermiştir. Nemli vadi içlerinde ise kavak (Populus sp.) ve söğüt (Salix) ağaçları yayılış gösterir (Çırpıc1, 1985; Günal, 2003; Semenderoğlu ve Aytaç, 2005). 


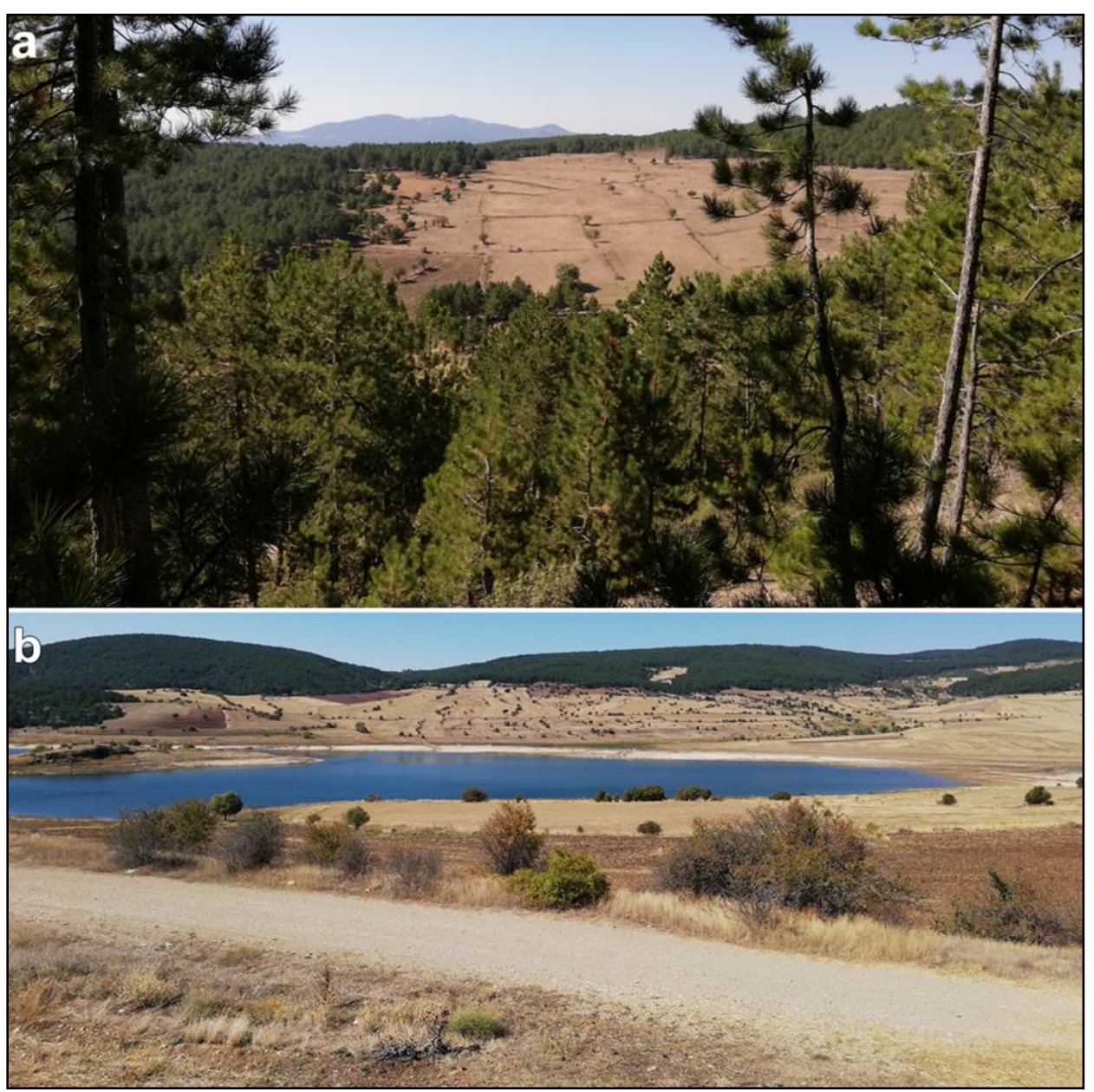

Foto 1. Fosil ormanın genel görünümü a) Sakızocak Tepe (1543 m) doğusu Tazılan Burnu petrifiye alanı, b) Küçükler Barajı batısı Alanyaka petrifiye alanı.

Silisleşmiş ağaçların bulunduğu saha ve çevresinde jeolojik olarak, Paleozoik döneme ait metamorfik, Mesozoik zamana ait tortul, ultrabazik ve silisifiye kayaçlar ile Tersiyer'e ait sedimanter, andezit, riyolit gibi volkanik birimler yayılış gösterir (Şekil 2).

Çokrağan Mağarası ve çevresinde, Çalüstü Tepe kısmında kristalize kireçtaşı, dolomitik kireçtaş1 ve dolomitlerden oluşan Çiçeklikaya formasyonu yüzeylenir. Birimi, Bingöl (1977) Çiçeklikaya kireçtaşı, Öztürk ve Karadağ (2009) tarafından ise Çiçeklikaya formasyonu olarak adlandırılmıştır. Formasyona, Günay vd. (1986) içindeki fosillere dayanarak Jura yaşını vermişlerdir.

Araştırma alanında en yaygın litolojik birim, allokton ultramafik kütleler ve ofiyolitik karmaşıktan oluşan Murat Dağı melanjıdır. İlk olarak Bingöl (1977) tarafından adlandırılmıştır. Geniş yüzlekler veren birim, ultramafik kütleler ile radyolarit, çört, kireçtaşı, kumtaş1 ve amfibolitik kayaçlardan oluşur. Murat Dağı melanjı içerisinde aynı zamanda ultrabazik peridotit, serpantinit gibi kayaçlar da mevcuttur (Yüksel vd., 2014). Birim bölgesel metamorfikler üzerinde uyumsuz bir şekilde bulunur. Ultrabazik kayaçların bazı kısımları Tersiyer sırasında silisifiye kayaç halinde altere olmuştur. Birim Küçükler köyü kuzeyinde, Küçükler Barajı aksı doğu ve batısında, Baybuyan Dere vadisinde, Kazıkbatmaz Tepe, Kara Tepe, Çamsu köyü kuzeyindeki Kayalı Dere vadisi içinde yayılış gösterir 
(Şekil 2). Murat Dağı melanjı adı altında ayırtlanan Geç Kretase yaşındaki bu birim, daha yaşlı birimler üzerine, tektonik dokunakla oturur (Günay vd., 1986).

Ancak melanj üzerinde özellikle İlkburunçeşme Sırtı, Tozlakgedik ve Kazıkbatmaz Tepesi arasında silis şapka oluşumları gözlenmiştir. Bu silisifiye oluşumlar, kırmızımsı, kahverengimsi, kızılkahve bir renk sunarlar. Bu seviyeler, kısmen kırmızımsı-kahverengimsi renkte ayrışmış bir özellik göstermelerine rağmen oldukça sert, silisli kayaçlardan oluşurlar. Kaya Tepe, Badırga Sırtı ve Büyükgür Sırtı civarlarında da kırmızımsı, kahverengimsi renkte lateritik depolar yüzeylenir (Öztürk ve Karadağ, 2009).

Çokrağan Kaynăğ kuzeyindeki Göktaş Dere vadisinde kırmızımsı, kahverengi ofiolit çakılları içeren Paleojen yaşlı Küllücetepe formasyonu özellikle ultramafitlerin sınırında gözlenmiştir. Öncelikle ultramafitlerin üst yüzeylerinin ayrışma ve alterasyona uğradığını, daha sonra monojenik yapısından dolayı ultramafitler üzerinde gelişen akarsuların bu kısımları taşıyarak eğimi az olan bölgelerde biriktirdiğini göstermektedir. Birimin çakıl boyutlarının, ultramafitlere yakın yerlerde büyük ve köşeli, uzaklaştıkça yuvarlak ve küçük olması, akarsuların etkisini göstermektedir. Formasyonun yaşı, Bingöl (1977), Öztürk ve Karadağ (2009) tarafindan Paleojen, Günay vd. (1986) tarafından üstüne gelen Yeniköy formasyonuna ve bölgesel karşılaştırmalara göre Erken (?)-Orta Miyosen olarak kabul edilmiştir. Küllüce tepe formasyonu ve Murat dağı melanjı üzerinde gelişen kırmızı-bordo renkli laterit oluşumlar, ağır ve kıymetli nikel, kobalt gibi metal oluşumları bakımından ekonomik öneme sahiptir.

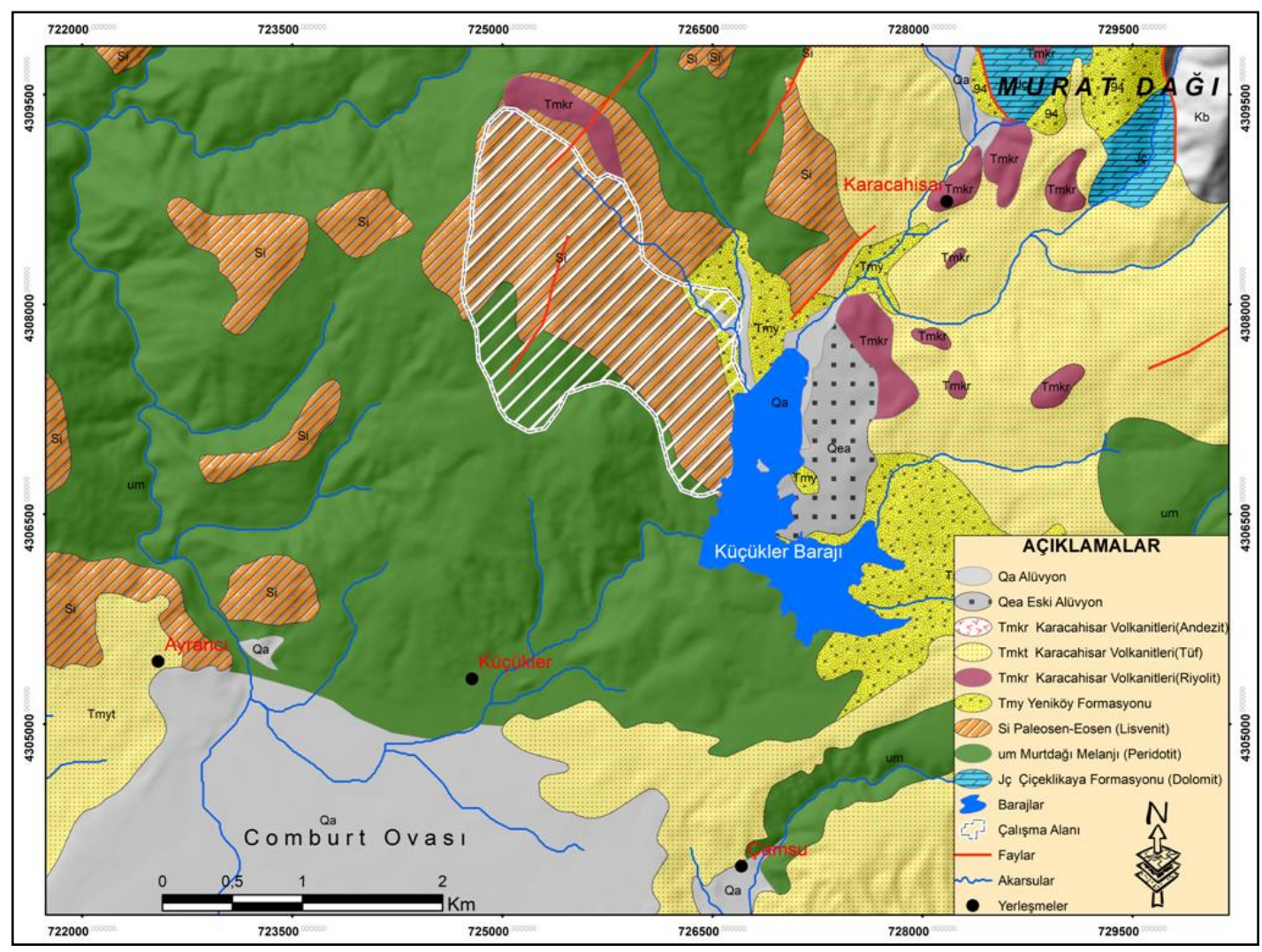

Şekil 2. Araştırma alanının jeoloji haritası (MTA Yerbilimleri Harita Görüntüleyici ve Çizim Editörü’nden faydalanılarak hazırlanmıştır). 
Karacahisar volkanitleri, metamorfikleri, ultrabazik kayaçları ve Tersiyer sedimentleri örter. Riyolit, dasit (kısmen andezitik) ve dasitik tüflerden oluşan volkanitler, Yukarı Karacahisar köyü ve dolaylarında yüzeylenir. Bu yerleşmenin içinde ve çevresinde sivri tepeler halinde gözlenmekte olan riyolitler, muhtemelen kloritleşme ve epidotlaşmaların yoğun olduğu yerlerde yeşilimsi-gri renklerde olup, porfirik dokularıyla karakteristiktir. Genellikle sert yapılı olan birim, K-Ar metoduyla jeokronolojik inceleme yapılmıştır. Bulunan radyometrik yaş değeri 16.9-20.9 milyon olup, Orta-Geç Miyosen'e tarihlendirilmiştir (Minareci, 2005).

Orta-Geç Miyosen yaşlı Yeniköy formasyonu ise Çamsu yerleşmesi doğusunda yüzeylenir ve gölsel ortamda çökelmiştir. Yatay olan formasyonu konglomera, kumtaşı, kiltaşı ve marn tabakaları oluşturur. Birim içinde Geç Miyosen'e ait omurgalı hayvan fosilleri Çamsu (Ceçe) köyü kuzeybatısında tespit edilmiştir (Yalçınlar, 1947).

Silisleşmiş fosil ağaçların tamamı Geç Kretase zamanına ait Murat Dağı melanjının üst seviyelerinde silisifiye oluşumlarla birlikte bulunan kırmızımsı, kahverengimsi, kızıl-kahve renge sahip lateritik depolar içinde bulunur. Birim, büyük oranda erozyonal faaliyetler nedeniyle aşınmış bazı yerlerde taşınarak yamaçlarda kırmızı depolar şeklinde kalmıştır. Kara Tepe çevresinde olduğu gibi üzerindeki silisifiye kayalar sayesinde korunup günümüze ulaşabilmiştir.

Silisleşmiş ağaçların, Geç Kretase zamanına ait Murat Dağı melanjı üzerinde kırmızı lateritler içerisinde yer alması, Küçükler Barajı kuzeyinde yayılış gösteren Küllücetepe formasyonu tarafından örtülmesi, ayrıca diğer jeolojik gözlemlerden dolayı (Şekil 3) yaşının Paleojen olduğu kanısına varılmaktadır.

\section{Materyal ve Yöntem}

Araştırmanın temel materyalini oluşturan silisleşmiş ağaç örnekleri Banaz (Uşak) batısında Küçükler yerleşmesi kuzeyinde Kara Tepe, Alan Tepe, Söpseke Sırt1, Sakızocak Tepe, Tuzlagedik Tepe arasında kalan alanda 1250-1500 m yükseltileri arasında Paleojene ait kırmızımsı-kahverengi silisli lateritik depolar içerisinde, iş makineleri tarafından açılan yol yarmalarında açığa çıkan mostralardan ve tarla kenarlarından toplanmıştır. Boyutları 10-30 cm arasında değişen 26 adet numune toplanarak, GPS ile koordinat ve yükselti bilgileri kaydedilmiştir. Araştırma alanında farklı konuma sahip alanlardan dokusal olarak farkl11ık arz eden silisleşmiş ağaç fosil numunelerinin seçilmesine özen gösterilmiştir.

Numuneler İTÜ Maden Mühendisliği İnce Kesit Atölyesi'nde enine, radyal ve teğet yönlerde olmak üzere ince kesitleri üç yönlü alınarak hazırlanmıştır. Örneklerin teşhisleri İstanbul ÜniversitesiCerrahpaşa Orman Fakültesi Orman Botaniği Anabilim Dalı'nda gerçekleştirilmiştir.

Araştırma alanında ağaç fosillerinin yaşı içinde bulunduğu formasyonun ait olduğu jeolojik döneme göre tespit edilmiştir. Ağaç fosillerinin hangi jeolojik döneme ait olduğunu tespit etmek için araştırma alanında hangi jeolojik birimlerin ağaç fosillerini ihtiva ettiği ile ilgili detaylı arazi gözlemleri yapılmıştır. Sahada Paleojen'e ait silisli lateritik depolar içerisinde ağaç fosillerinin bulunması sebebiyle ağaç fosillerine Paleojen yaşı verilmiştir. Teşhis edilen ağaç türünün günümüzde yayılış gösterdiği sahaların coğrafi, ekolojik ve klimatolojik özelliklerinden yola çıkarak araştırma alanının Paleojen dönemi paleocoğrafyası, paleoekolojisi ve paleoklimatolojisine dair değerlendirmeler yapılmıştır. 
Araştırma alanını içine alan 1/25000 ölçekli K23 a1, a2, a3,a4 topografya haritaları temin edilmiştir. Topografya haritasından sayısallaştırma yoluyla elde dilen izohips verisi kullanılarak araştırma alanının $10 \mathrm{~m}$ çözünürlüklü sayısal yükseklik modeli oluşturulmuştur. Jeolojik formasyonlarla ilgili veri Maden Tetkik Arama Müdürlüğü'nün Yerbilimleri Harita Görüntüleyici ve Çizim Editörü'nden değiştirilerek oluşturulmuştur. Bütün haritalama işlemleri ArcGIS 10.5 yazılımı ile yapılmıştır.

\section{Bulgular}

\subsection{Fosil Orman Alanına İlişkin Bulgular}

Silisleşmiş ağaçlar, Sakızocak Tepe (1543 m) doğusunda Tazılan Burnu mevkiinde karaçam (Pinus nigra Arn. subsp. pallasiana) ve titrek kavak (Populus tremula) türlerinden oluşan orman içinde ve Küçükler Barajının batısındaki tarım arazilerinin bulunduğu alanda yer alır (Foto 2) ve tarım arazilerinin bulunduğu alanda sayıları daha da artar. Yukarı Karacahisar köyü sakinleri, fosilleri tarımsal faaliyetlere engellediği düşüncesi ile tarla sınırlarına, tarla kenarlarına aynı zamanda tarla içinde yer alan kayaç kümelerinin içine atmışlardır. Bunun yanında Küçükler köyünü Murat Dağı termal kaynaklarına bağlayan stabilize karayolunun yapımı sırasında ortaya çıkmış çok sayıda blok şeklinde fosiller bulunmaktadır. Fosil ağaçlarda dokusal özellikler çok belirgindir. $1.5 \mathrm{~m}$ uzunluğunda ve maksimum $70 \mathrm{~cm}$ kalınlığında kütleler halindedir. Silisleşmiş ağaçlar, baskın olarak ağaçların gövde ve kök kısımlarını içerir ve bunların tamamı yatık halde bulunmaktadır. Bu nedenle taşınarak gelmiş olma olasılı̆̆ yüksektir.

Silisleşmiş ağaçların bulunduğu alan bütünüyle Geç Kretase yaşlı ofiolitlerden oluşmaktadır. Fosiller, ofiolitlerin üzerinde şapkalar halinde bulunan maksimum kalınlığı 30 metreye kadar çıkan, nikel, kobalt ve demir içeren kırmızı ve kahverengi ile dikkati çeken lateritik depolar içinde görülür. Bazik ve ultrabazik ana kayanın kimyasal çözünmesi ile oluşmuş olan bu lateritik depolar, büyük oranda erozyonal faaliyetler nedeniyle aşınmıştır. 

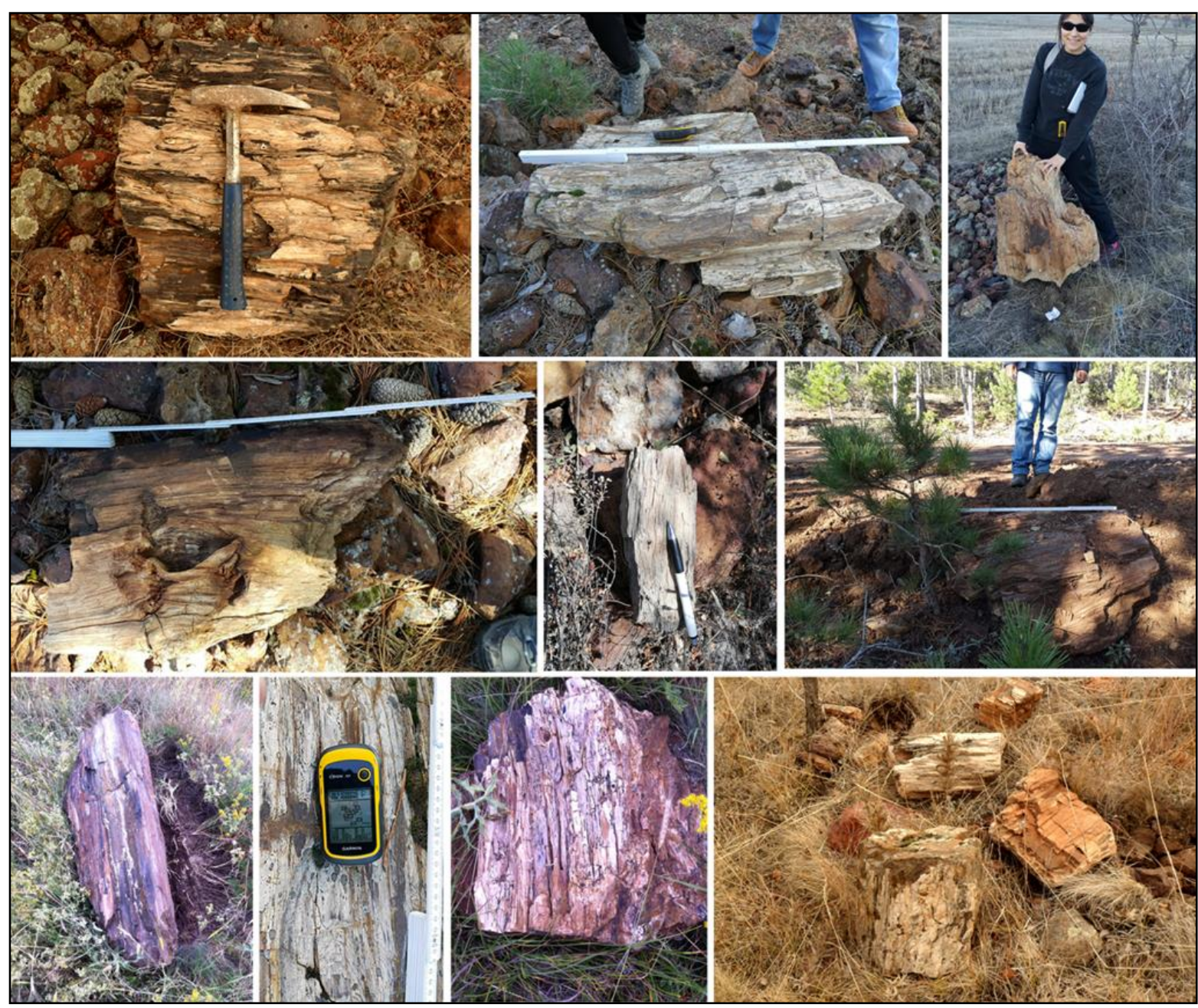

Foto 2. Araştırma alanından silisleşmiş ağaç fosil örnekleri.

Sahanın kuzeyinde Yukarı Karacahisar ve güneyinde Elmadağı çevresinde volkanik çıkışlar olsa da buradaki silisleşmiş ağaçlar lateritik depolar içinde yer almaktadır. Başka bir ifade ile ağaçların fosilleşmesinde volkanik aktivitenin etkisi tespit edilememiştir.

Kuzey Neotetis okyanusal litosferin kalıntıları olan Murat Dağı melanjı, Geç Kretase zamanında Menderes Platformu'nun kuzeydoğu kenarı üstüne yerleşmiştir. Bu melanja ait ofiyolitler Paleojen (özellikle Oligosen) zamanı süresince nemli tropikal iklim ve kimyasal ayrışma şartları altında lateritleşmiştir. Miosen döneminde, Murat Dağı blok faylanmalar ile gerilme tektoniğinden yoğun olarak etkilenmiştir (Ardos, 1979). Böylece, aktif tektonik olaylar ile parçalanmış içinde petrifiye barındıran lateritik alanlar farklı yükseltilere çıkmıştır.

\subsection{Silisleşmiş Ağaçların Tanısı}

Üç yönlü olarak alınan ince kesitlerde aşağıda belirtilen özellikler tespit edilmiştir.

Enine kesit (TS): Yıllık halka sınırı belirgin ve genişlikleri 0,3-1 mm'dir. İlkbahar odunundan yaz odununa geçiş ani ve yaz odunu bandı genişliği 2-15 hücre olup radyal çapları belirgin şekilde daralmıştır. Bazı yıllık halkalarda da geçiş yavaştır. Boyuna paranşimler yaygın ve dağınık olup teğet bantlar halinde, yıllık halka sınıında ya da yaz odununa geçişte yer almıştır (Levha 1). 
Teğet kesit (TLS): Öz 1şınları baskın bir şekilde tek sıralı, yüksekliği 5-40 hücre kadar olup bazı öz ışınları kısmen iki sıralıdır. Traheidlerde spiral kalınlaşma bulunmamaktadır. Boyuna paranşim hücrelerinin enine çeperleri düzdür. Bazı boyuna paranşim hücrelerinde kahverengi içerik bulunmaktadır (Levha 1).

Radyal kesit (RLS): İlkbahar odunu traheidlerininradyal çeperlerindeki kenarlı geçitler genellikle 1-2 sıralı, yaz odununda ise bir sıralıdır. Öz ışınlarının sınırlarında enine traheid yoktur. Çift sıralı kenarlı geçitlerde krasül oluşumu gözlemlenmiş olup fosilleşme esnasında bozulma fazla olduğu için belirgin şekilde fotoğraflanamamıştır. Karşılaşma yeri geçitleri taxodioid tipte olup bozulmanın fazla olması nedeniyle kısmen görülebilmektedir. Öz ışınlarının çeperleri düz ve geçitsizdir.

Tespit edilen özelliklerden taxodioid tipte karşılaşma yeri geçitlerinin varlığı, yıllık halka sınırının görülmesi, boyuna parankima hücrelerinin dağınık ya da yer yer teğet bantlar halinde olması örneklerin Cupressaceae (Taxodiaceae) familyasına ait olduğunu göstermektedir. Bu familya içerisinde en yaygın bulunan ağaçlar, burada da tespit edilmiş olan sekoya grubu (Sequoioxylon) ağaçlarıdır. Sequoioxylon familya içerisinde Sequoia, Sequoiadendron ve Metasequoia cinslerinin üçü için ortak kullanılan isimdir. Bu üç cins birbirine çok benzediğinden birbirlerinden ayırt edilmesi olanaklı değildir. O nedenle Sequoioxylon adiyla anılmaktadır.

\section{Tartışma ve Sonuç}

Taxodiaceae odunları ülkemizde Geç Oligosen'den Pliyosen'e kadar farklı bölgelerde yaygın olarak görülmektedir (Akkemik vd., 2009; Akkemik ve Sakınç, 2013; Akkemik, 2019; Aras vd., 2003; Eroskay ve Aytuğ 1982; Kayacık vd., 1995; Özgüven 1971, 1981 (1983); Sakınç vd., 2007). Tanıs1 yapılan örneklerde başta karşılaşma yeri geçitleri olmak üzere odunsu dokularda bozulmalar olduğu için tanı cins düzeyinde bırakılmıştır.

Sequoia tipi ağaçların varlığı yaşam alanlarının, çevresinde 1lıman iklim koşullarının hâkim olduğu bataklık ormanı ya da dere kenarı vejetasyonunun (riperian vejetasyonu) bulunduğunu göstermektedir. Bu yapı Paleojen, Erken Miyosen boyunca Türkiye ve Yunanistan'ın içinde bulunduğu geniş bir alanda hüküm sürmüştür (Akgün vd., 2007; Akkemik vd., 2016; Akkiraz vd., 2011; Bayam vd., 2018; Bouchal vd., 2016; Bouchal vd., 2017; Denk vd., 2017a, b, c; Güner vd., 2017; Velitzelos vd., 2014) (Şekil 3). Günümüzde ülkemizde doğal olarak yayılışı bulunmayan bu ağaçların temsilcileri Kuzey Amerika'nın Kaliforniya sahilleri ve Çin'in güneyindeki nemli ve derin topraklı akarsu kenarlarında yaşamaktadır. 

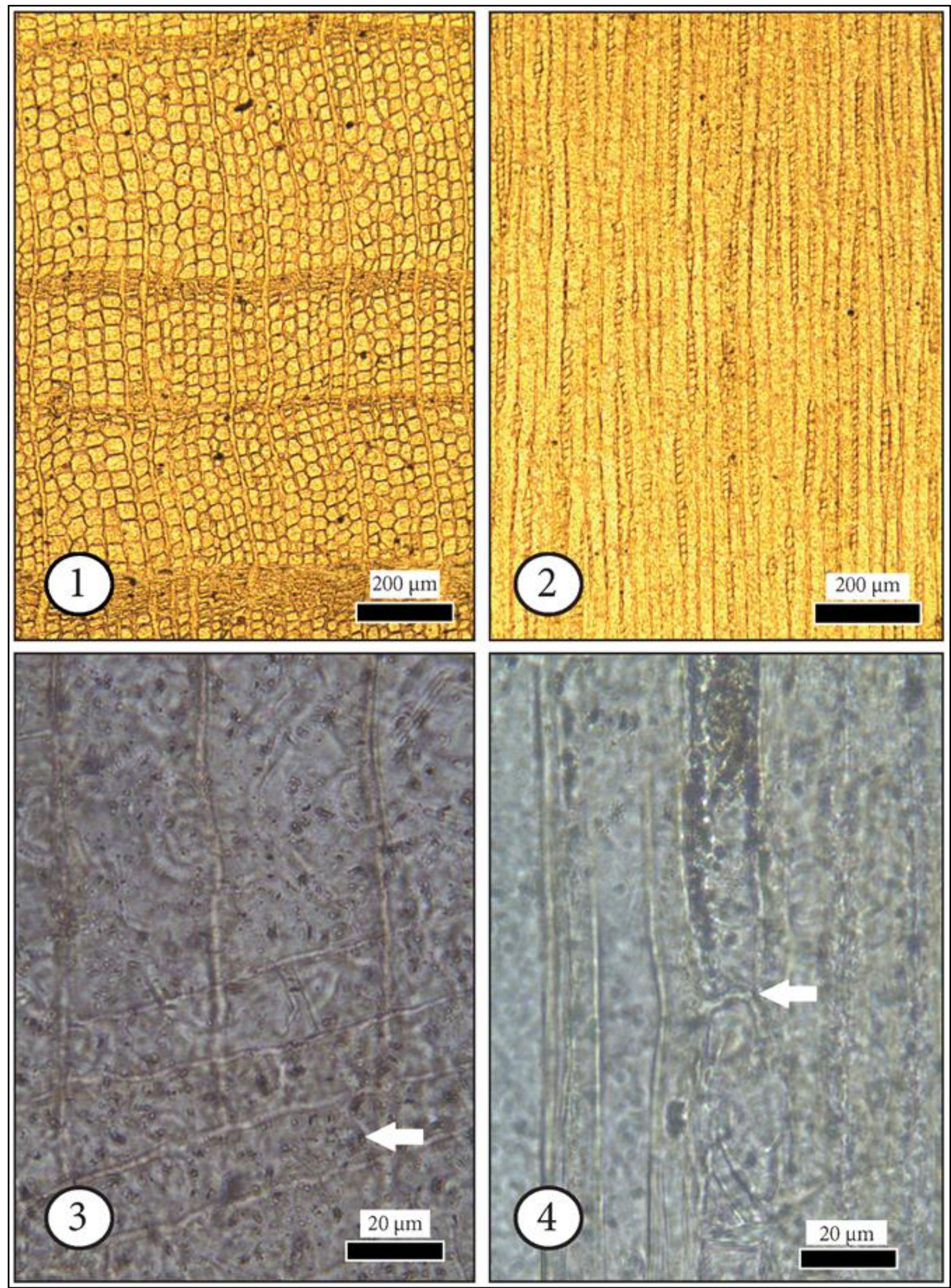

Levha 1. Sequoioxylon Torrey 1923. 1)Yıllık halka sınırı ve ilkbahar-yaz odunu geçiși belirgin, yaz odunu zonu 2-12 sıra traheidden oluşan ve odun parankima hücreleri yaz odununda dağınık durumda olan enine kesit, 2) Özışııı yüksekliği 5-40 hücre arasında değişen teğet kesit, 3) Karşılaşma yeri geçitleri taxodioid tipte olan radyal kesit. Fosilleşme koşullarından dolayı karşılaşma yeri geçitleri fazla belirgin değildir (beyaz ok), 4)Enine çeperleri düz olan boyuna parankima hücreleri (beyaz ok). 


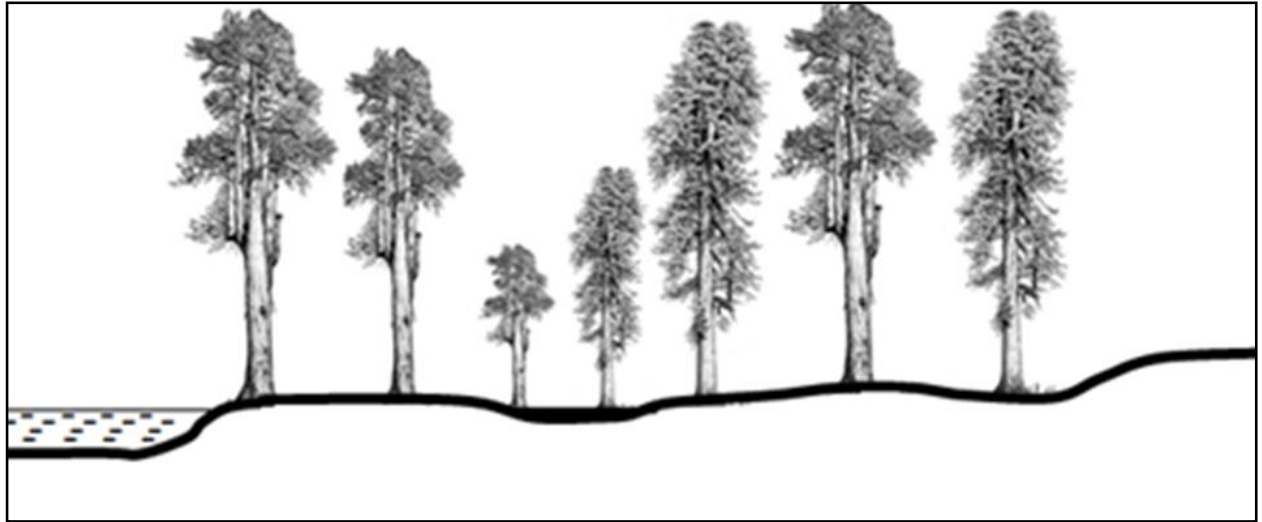

Şekil 3. Sekoya (Sequoioxylon) grubu ağaçlardan oluşan olası orman yapısı.

Yukarı Karacahisar köyü güneybatısındaki silisleşmiş ağaçların tanısı yapılarak tamamının Sequoioxylon'lara ait olduğu sonucuna varılmıştır. Başka ağaç türlerine ait fosiller tespit edilememiştir. $\mathrm{Bu}$ durum alanda sekoyaların saf topluluk oluşturduğu sonucuna götürmektedir. Fosiller, bölgenin Eosen-Oligosen (Paleojen) jeolojik zamanının orman yapısı, iklim özellikleri ve toprak şartları hakkında bilgi vermesi açısından önemlidir. Ayrıca fosil ağaçların türü bölgede iklimin 1lıman olduğunun göstergesidir. Nitekim Sequoia cinsi, Kretase'den Miyosen dönemine kadar tüm Avrupa, Anadolu ve Asya'da yaygın ve çok sayıda değişik formla temsil edilirken günümüzde sadece Kuzey Amerika'nın Kaliforniya sahillerine yakın yerlerde kalmış olan ve dünyadatek türle temsil edilen "monotipik" bir cinstir (Akkemik, 2018). Günümüzde bu alanların iklim özelliklerine baktığımızda yıllık yağış miktarının 800-1750 mm arasında değiştiği, yıllık ortalama sıcaklığın ise $9-14{ }^{\circ} \mathrm{C}$ arasında seyrettiği belirtilmektedir. Ayrıca Sequoioxylon'ların kritik dayanma gücünün $-12{ }^{\circ} \mathrm{C}$ civarında olduğu en kurak ayın ortalama yağış miktarının $30 \mathrm{~mm}$ den daha az olmaması gerekmektedir (Wilson vd., 2016)

Silisleşmiş ağaçlar, günümüzde 1250-1450 metre yükselti basamağı arasında kalan alanda yayılış gösterir. Araştırmalarımıza göre en büyük fosil ağaç $1.5 \mathrm{~m}$ uzunluğundadır. Maksimum çap ise 70 cm'ye kadar çıkmaktadır. Ağaç fosillerinin parçalı ve yatık olması buraya taşınarak gelmiş olma olasılığını kuvvetlendirmektedir. Silisleşmiş ağaçlar, Türkiye'nin diğer yerlerinde olduğu gibi volkanik etkinlik sonucunda fosilleşmiş değildir. Lateritik depolar içinde silisleşmiş ağaçların dağınık halde, aşırı derecede parçalanmış şekilde bulunması taşınmış olduğunu, fosilleşmenin sel-taşkın olayları sonucu meydana gelmiş olabileceği ihtimalini güçlendirmektedir.

Murat Dağı'nda varlığı tespit edilen bu fosil ağaçların bulunduğu saha herhangi bir koruma statüsüne sahip değildir. Fosillerin bulunduğu alanlar ve sınırları tam olarak tespit edilerek koruma altına alınmalıdır. Fosil örneklerinin yerinde korunması konusunda gerekli çalışmaların bir an önce yapılması gerekmektedir. Sahanın açık hava müzesi olarak düzenlenmesi bilimsel, eğitimsel, sosyo-ekonomik açıdan yöreye birçok yarar sağlayacaktır.

Türkiye'nin ender jeositlerden biri olan Yukarı Karacahisar ağaç fosillerinin içinde yer aldığ 1 sahada lateritik depo içindeki nikel gibi metallerin çıkarılmasına yönelik yapılması düşünülen madencilik faaliyetlerine izin verilmemelidir. İzin verildiği takdirde yöredeki doğal bitki örtüsü tahrip 
olacağı gibi jeolojik zamanın kayıtlarını bünyesinde barındıran ağaç fosilleri de yok edilme riskiyle karşı karşıya kalacaktır. Diğer önemli tehdit unsurlarından biri de fosillerin koleksiyoncular tarafından toplanması ve ticari meta olarak satılmasıdır. Bu jeolojik mirasın zarar görmemesi için yöre halkının, ağaç fosilleri ve fosil orman hakkında bilgilendirilmesi ve bilinçlendirilmesi konusunda gerekli eğitim çalışmalarının yapılması gerekmektedir. 


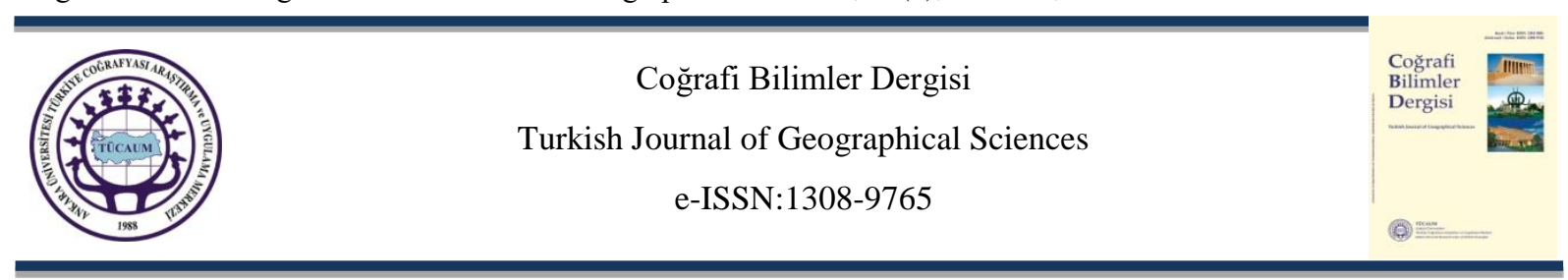

\title{
The first findings on fossil trees area located in Banaz (Uşak)
}

\author{
Selahattin Polat ${ }^{\mathrm{a}}$, Yıldız Güney*b, İsmail Ege ${ }^{\mathrm{c}}$, Ünal Akkemik ${ }^{\mathrm{d}}$
}

\section{EXTENDED ABSTRACT}

\section{Introduction}

Silicified trees and fossil forests are important heritage sites for understanding natural history as well as paleoclimatological and paleogeographic changes taking place in a certain region. Such fossil forests also exist in Turkey. Studies on petrified in Turkey have increased recently on different geological periods ranging from the Oligocene Era to the Pliocene Era are the main fields of study are the East Thrace Ergene basin (Akkemik et al., 2005), Çamlıdere-Pelitçik village (Akkemik et al., 2009), Seben-Hoçaş village (Akkemik et al., 2016), Güdül (Akkemik et al., 2017), Haymana (Akkemik et al., 2018), Galatya Massive (Bayam et al., 2018), Gökçeada (Güngör et al., 2019) North of Istanbul (Akkemik et al., 2019) and around Kütahya (Akkemik et al., 2019). Fossil trees are generally difficult to come across as a whole, but rather encountered as remains. Since research on macro fossils and micro fossils in Turkey have begun to increase in recent years, paleogeography findings belonging from Late Oligocene to Pliocene Era have reached an important level.

The purpose of this study is to share the first findings on the silicified fossil trees of Yukarı Karacahisar (Banaz) which were discovered for the very first time by us. Fossils and fossil wood found in other regions of Turkey are distinguished by the presence of silicified density and a fairly thick trunk. Other known fossil trees are found in the village of Osmancalı (Manisa) in the Aegean Region (Yurtseven, 2018). Fossil trees are important for they reveal the paleogeography and paleoecology of the geological period in belongs to and provide data on the evolution of Anatolia. In other words, these silicified tree fossils capture and maintain a record of the past.

Location of Petrified Area and General Physical Geography Features

Yukarı Karacahisar fossil trees are located $40 \mathrm{~km}$ northeast of Uşak city center, by the roadside. This area is located within the borders of the Yukarı Karacahisar village of Banaz district and southwest of the settlement. The fossils are scattered around an area of approximately $3.1 \mathrm{~km}^{2}$. The petrified area -bounded by the Küçükler Dam from the east- is located in the area between Mestalanı stream in the north and Kara stream in the south.

\footnotetext{
*Corresponding Author: Yıldız Güney, yildiz.guney@ gmail.com

aUsak University, Faculty of Arts and Sciences, Geography Department, Usak, Turkey, http://orcid.org/0000-0002-8042-1918

${ }^{\mathrm{b}}$ Usak University, Faculty of Arts and Sciences, Geography Department, Usak, Turkey, http://orcid.org/0000-0002-0756-9246

${ }^{c}$ Usak University, Faculty of Arts and Sciences, Geography Department, Usak, Turkey, http://orcid.org/0000-0001-5896-0440

${ }^{\mathrm{d} I s t a n b u l ~ U n i v e r s i t y-C e r r a h p a s ̧ a, ~ F a c u l t y ~ o f ~ F o r e s t r y, ~ D e p a r t m e n t ~ o f ~ F o r e s t ~ E n g i n e e r i n g, ~ I s t a n b u l, ~ T u r k e y, ~}$ http://orcid.org/0000-0003-2099-5589
} 
Based on the data supplied by Uşak and Gediz Meteorological Stations, the annual average temperature is around $9{ }^{\circ} \mathrm{C}$ in the vicinity of the research area whilethe annual rainfall is estimated to be 800-900 mm.

Murat Mountain hosts plants belonging to the Euro-Siberian, the Mediterranean and the IranTuranian phygeographical regions. Silicified trees are found in the south of Murat Mountain where the dry forest spreads at the present time. Although the dominant plant species is Anatolian Black Pine (Pinus nigra Arnold subsp. pallasiana), there are also small Eurasian aspen (Populus tremula) populations and Rockrose (Cistus laurifolius.), Poplar (Populus sp.) and Willow (Salix sp.) trees spread in the moist valley.

Geologically, Paleozoic metamorphic rocks, Mesozoic sedimentary rocks, ultrabasic rocks and silicified rocks, Tertiary sedimentary, andesite, rhyolite such as volcanic units are present in this area. The most common lithological unit in the research area is the Murat Mountain mélange consisting of allochthonous ultramafic masses and ophiolitic complex. It lies discordantlyon the metamorphic rocks (Bingöl, 1977).

The Çiçeklikaya Formation, which consists of crystallized limestone, dolomitic limestone and dolomite belonging to the Jurassic geological period, is seen in the study area. At the same time, Murat Mountain mélange consists of radiolarite, chert, limestone, sandstone and amphibolitic rocks as well as containings ultrabasic peridotite and serpentinite. As observed between the İlkburunçeşme ridge, Tozlakgedik and Kazıkbatmaz Hill, especially silica cap formations were also identified on the formation. Ultramafic rocks of Paleogene ophiolite pebbles are found on the mélange. Nearby of the study area Küllücetepe Formation is large and angular, but farther of the center they are small in size, and formed by the influence of streams (Öztürk and Karadağ, 2009).

Sharp hills forming due to volcanic activity as a like rhyolite, dacite and dacitic tuff spread around Karacahisar settlement (Minareci, 2005).

Yeniköy Formation which is Middle-Late Miocene consists of conglomerate, sandstone, claystone and marl layers. It has vertebrate animal fossils (Yalçınlar, 1946).

All of the silicified fossil trees are found in reddish, brownish, red-brown lateritic deposits with silicified formations at the upper levels of the Murat Mountain mélange of the Late Cretaceous. The unit of they were transported with erosion direction of slope on some places due to erosional activities and some of them were remained in the form of red deposition the strike of Murat Mountain.

It appears that the silicified trees are located in the red laterites on the Murat Mountain mélange of the Late Cretaceous period, and are covered by the Paleogene Küllücetepe Formation of reddish, brown ophiolite pebbles spreading to the north of Küçükler Dam, and due to other geological observations, its age is Paleogene.

\section{Material and Method}

The basic material of this research consists of silicified wood samples gathered from the area between Kara hill, Alan hill, Söpseke ridge, Sakızocak Hill and Tuzlagedik Hill in the north of Küçükler settlement (in the northwest of Banaz district of Uşak) and, in the reddish-brown siliceous lateritic 
deposits belonging to Paleogene, between 1250-1500m elevations. They appear on the outcrops and field boundaries exposed in road splits opened by construction machinery.

A total of 26 specimens ranging between 10 to $30 \mathrm{~cm}$ in size were collected, and their coordinate, and altitude information was recorded by GPS. Care was taken to select texturally different fossils from different locations.

Samples were prepared at ITU Mining Engineering Thin Section Workshop by taking three thin sections in transverse, radial and tangential directions. Thus, the identification of the samples was carried out in Istanbul University-Cerrahpaşa Forestry Faculty, Forest Botany Department. Detailed field observations were made in the research area to determine the geological period to which the tree fossils belong.

1/25 000 scale K23a1, a2, a3, a4 topography maps covering the study area were provided for research. Different maps (such as location, geology and physical) were created with ArcGIS 10.5 software based on the data collected.

\section{Findings}

Silicified trees are located in the forest of the Anatolian Black Pine (Pinusnigra Arn. subsp. pallasiana) and Eurasian aspen (Populus tremula) species in the Tazllanburnu locality east of Sak1zocak Hill $(1543 \mathrm{~m})$ and in the area where the agricultural lands to the west of Küçükler Dam are located. At the same time, they are observed in the rock clusters on the sides of the stabilized road that connects Küçükler village to the thermal springs of Murat Mountain.

Textural properties are very prominent in fossil trees. These are generally $1.5 \mathrm{~m}$ long and up to $70 \mathrm{~cm}$ in width. The silicified trees predominantly contain the trunk and root parts of the trees, all of which are horizontal position. Therefore, they are highly transported from the upper part of area. Fossils are seen in lateritic depots of red and brown and nickel, cobalt and iron containing maximum thickness up to 30 meters in as a like hats on ophiolite rocks.

Fossil trees were thin sectioned along three planes transverse section (TS), radial longitudinal section (RLS), and tangential longitudinal section (TLS), and were studied using a transmitted light microscope. Descriptions follow the terminology of the IAWA Committee (2004) where ever possible. Identifications were made following reference towell-described extant wood, preferably voucher specimens, housed in the Forest Botany Department, Faculty of Forestry, Istanbul University. Petrifices of the identified properties indicate that they belong to the Cupressaceae (Taxodiaceae) family. The most common trees, identified here, in this family are redwood (Sequoioxylon) trees. Sequoioxylon (redwood) is a common name in the family for three of Sequoia, Sequoiodendron and Metasequoia. Since these three genera are very similar, it is not possible to distinguish each other. It is therefore called Sequoioxylon (redwood).

\section{Discussion and Results}

Taxodiaceae firewood is widely seen in different regions from Late Oligocene to Pliocene eras in Turkey. The existence of Sequoia trees indicates that the habitats have swampy forest or riverside 
vegetation (riparian vegetation) with mild climatic conditions. Today, the representatives of these trees, which do not naturally grow in our country, live on the California coast of North America and on the edges of moist and deep soil streams in the south of China.

The Silicified trees identified in the southwest of Yukarı Karacahisar village showed that they all belong to Sequoioxylons. Fossils belonging to other tree species were not identified. This shows that the redwoods constitute pure communities in the area. The Yukar1 Karacahisar tree fossils have been assigned Paleogene age because they are found in Paleogene siliceous lateritic deposits.

Petrifies are important in terms of providing information about forest structure, climate characteristics and soil conditions of the Eocene-Oligocene (Paleogene) geological time of the region (Özgüven 1971; Eroskay and Aytuğ 1982; Kayacık at al., 1995; Aras et al., 2003; Sakınç et al., 2007; Akkemik et al., 2009; Akkemik and Sakınç, 2013). In addition, the type of fossil trees is an indicator that the climate in the region is mild.

Nowadays, when we look at the climatic characteristics of the areas where these trees exist, which remain close to the California coast of North America, the annual rainfall varies between 800 $1750 \mathrm{~mm}$ and the average annual temperature is between $9-14^{\circ} \mathrm{C}$. In addition, the average rainfall of the driest month in which the critical stamina of Sequoioxylons is around $-12^{\circ} \mathrm{C}$ should not be less than 30 $\mathrm{mm}$.

Silicified trees near the village of Yukar1 Karacahisar are spread in the area between the elevation step of 1250-1450 meters. According to our research, the largest fossil tree is $1.5 \mathrm{~m}$ long. The maximum diameter is up to $70 \mathrm{~cm}$. The fact that, since tree fossils are clastic and horizontal position, we think that they have come here from upper section of study area.

These fossils are not fossilized in volcanic activity, as in other places in Turkey. The presence of silicified trees scattered in lateritic warehouses, being extremely fragmented, reinforces the possibility that they may have been caused by flood-flood events.

The area where the fossil trees have been found on Mount Murat is not under protection. Thus, the necessary studies on the conservation of fossil specimens should be carried out as soon as possible.

One of the rare geosite of Turkey is Karacahisar geosite fossil trees. These are situated in the laterite depositions. In here, mining activity will be started near future for the removal of metals such as nickel in laterite area. After the mining activity, fossils will be damage. In this area, mining activities should not be allowed. One of the threatening elements of petrifies is the collection and sale of commercial commodities by collectors.

\section{Referanslar/References}

Akgün, F., Kayseri, M. S., Akkiraz, M. S. (2007). Paleoclimatic evolution and vegetational changes during the Late OligoceneMiocene period in western and central Anatolia (Turkey). Palaeogeography, Palaeoclimatology, Palaeoecology, 253, 56-90. https://doi.org/10.1016/j.palaeo.2007.03.034

Akkemik, Ü., Sakınç, M. (2013). Sequoioxylon petrified woods from the Middle to Late Oligocene of Thrace (Turkey). IAWA Journal, 34 (2), 177-182. 
Akkemik, Ü. (2018). Türkiye'nin Doğal-Egzotik Ă̆açve Çalıları. Ankara: T. C. Orman ve Su İşleri Bakanlığı Orman Genel Müdürlüğü Yayını.

Akkemik, Ü. (2019). New fossil wood descriptions from Pliocene of central Anatolia and presence of Taxodioxylon in Turkey from Oligocene to Pliocene. Turkish Journal of Earth Sciences, 28, 398-409.

Akkemik, Ü., Acarca, N. N., Hatipoğlu, M. (2017). The first Glyptostroboxylon from the Miocene of Turkey. IAWA Journal, 38 (4), 561-570.

Akkemik, Ü., Akkılıç, H., Güngör, Y. (2019). Fossil wood from the Neogene of the Kilyos coastal area in Istanbul, Turkey. Palaeontographica Abteilung B Palaeobotany-Palaeophytology, 299 (1-6), 133-185.

Akkemik, Ü., Arslan, M., Poole, I., Tosun, S., Köse, N., Karlığlu Kılıç, N., Aydın, A. (2016). Silicified woods from two previously undescribed early Miocene forest sites near Seben, northwest Turkey. Review Palaeobotany Palynology, $235,31-50$

Akkemik, Ü., Atıcı, G., Poole, I., Çobankaya, M. (2018). Three new silicified woods from a newly discovered earliest Miocene forest site in the Haymana Basin (Ankara, Turkey). Review of Palaeobotany and Palynology, 254, 49-64.

Akkemik, Ü., Köse, N., Poole, I. (2005). Sequoioiodae (Cupressaceae) woods from the upper Oligocene of European Turkey (Thrace). Phytologia Balcanica, 11 (2), 119-131.

Akkemik, Ü., Türkoğlu, N., Poole, I., Çiçek, I., Köse, N., Gürgen, G. (2009). Woods of a Miocene petrified Forest near Ankara, Turkey. Turkish Journal of Earth Sciences, 33, 89-97.

Akkiraz, M. S., Akgün, F., Utescher, T., Bruch, A. A., Mosbrugger, V. (2011). Precipitation gradients during the Miocene in Western and Central Turkey as quantified from pollen data. Palaeogeography, Palaeoclimatology, Palaeoecology, 304, 276-290. https://doi.org/10.1016/j.palaeo.2010.05.002

Aras, A., Aksoy, N., Batu, Z., Sakınç, M., Erdoğan, M. (2003). Yaşayan fosil Sequoiadendron giganteum ağaçlı linyitleri ksiloloji palinoloji ve yaşı. Kuvaterner Çalıştayı IV, 39-30 Mayıs 2003, 107-120, İstanbul.

Ardos, M. (1979). Türkiye Jeomorfolojisinde Neotektonik. İstanbul: İstanbul Üniversitesi Yayınları.

Bat1, Z. (1996). Palynostratigraphy and Coal Petrography of the Upper Oligocene Lignites of the Northern Thrace Basin, NW Turkey. Ortadoğu Teknik Üniversitesi, Fen Bilimleri Enstitüsü, Yayınlanmamış Doktora Tezi, Ankara.

Bayam, N. N. A., Akkemik, Ü., Poole, I. \& Akarsu, F. (2018). Further Contributions to the early Miocene forest vegetation of the Galatian Volcanic Province, Turkey. Palaeontologia Electronica, 21 (3), 1-42.

Bingöl, E. (1977). Murat dağı jeolojisi ve ana kayaç birimlerinin petrolojisi. Türkiye Jeoloji Kurumu Bülteni, 20 (2), $13-66$.

Bouchal, J. M., Grímsson, F., Zetter, R., Denk, T. (2016). The middle Miocene palynoflora and palaeoenvironments of Eskihisar (Yatağan Basin, southwestern Anatolia): a combined LM and SEM investigation. Botanical Journal of the Linnean Society, 182, 14-79. https://doi.org/10.1111/boj.12446

Bouchal, J. M., Mayda, S., Akgün, F., Grímsson, F., Zetter, R., Denk, T. (2017). Miocene palynofloras of the Tinaz lignite mine, Muğla, southwest Anatolia: taxonomy, palaeoecology and local vegetation change. Review of Palaeobotany and Palynology, 243, 1-36. https://doi.org/10.1016/j.revpalbo.2017.02.010

Çırpıcı, A. (1985). Murat Dağı florası ve vejetasyonu üzerinde gözlemler. Doğa Bilim Dergisi, 9 (1), 40-47.

Denk, T., Grimm, G. W., Manos, P.S., Deng, M., Hipp, A. (2017c). An updated infrageneric classification of the oaks: review of previous taxonomic schemes and synthesis of evolutionary patterns. Gil-Peregrin, E., Peguero-Pina, J.J., SanchoKnapik, D. (Eds.) Oaks Physiological Ecology Exploring the Functional Diversity of Genus Quercus. Tree Physiology 7 içinde (13-38). Switzerland: Springer Nature.

Denk, T., Güner, T. H, Kvaček, Z., Bouchal, M. J. (2017a). The early Miocene flora of Güvem (Central Anatolia, Turkey): a window into early Neogene vegetation and environments in the Eastern Mediterranean. Acta Palaeobotanica (monograph), 57, 237-338. https://doi.org/10.1515/acpa-2017-0011

Denk, T., Velitzelos, D., Güner, T., Bouchal, J. M., Grimsson, F., Grimm, G. W. (2017b). Taxonomy and palaeoecology of two widespread western Eurasian Neogene sclerophyllous oak species: Quercus drymeja Unger and $Q$. mediterranea Unger. Review of Palaeobotany and Palynology, 241, 98-128. https://doi.org/10.1016/j.revpalbo.2017.01.005

Dernbach, U., Herbst, R., Jung, W., Schaarschmidt, F.,Selmeier, A. E., Velitzelos, D. (1996). Versteinerte Wälder. Die, 31, 1188.

Eroskay, O., Aytuğ, B. (1982). Doğu Ergene Çană̆ı'nın petrifiye ağaçları. İstanbul Üniversitesi Orman Fakültesi Dergisi, 2 (32), 7-21. 
Gemici, Y., Akyol, E., Akgün, F., Seçmen, Ö. (1991). Soma Kömür Havzası fosil makro ve mikroflorası. M. T. A. Dergisi, $112,161-178$.

Gümüş, E. (2008). Yeni Bir Doğa Koruma Kavramı: Unesco Jeoparklar Çerçevesinde Çamlıdere (Ankara) Fosil Ormanı Fizibilite Çalışması. Ondokuzmayıs Üniversitesi, Sosyal Bilimler Enstitüsü, Yayınlanmamış Yüksek Lisans Tezi, Samsun.

Günal, N. (2003). Yukarı Gediz Havzası'nın Bitki Coğrafyası. İstanbul: Çantay Kitabevi.

Günay, E., Akdeniz, N., Şaroğlu, F., Çağlayan, A. (1986). Murat Dă̆ı-Gediz Dolaylarının Jeolojisi. Ankara: MTA Jeolojik Etütleri Daire Başkanlığı, Rap. No: 8046.

Güner, H. T., Bouchal, J. M., Köse, N., Göktaş, F., Mayda, S. \& Denk, T. (2017). Landscape heterogeneity in the Yatağan Basin (southwestern Turkey) during the middle Miocene inferred from plant macrofossils. Palaeontolographica Abt. $B, 296$ (1-6), 113-171.

Güngör, Y., Akkemik, Ü., Kasapçi, C., Başaran, E. (2019). Geology and woods of a new fossil forest from the early Miocene of Gökçeada (Turkey). Forestist, 69 (1), 22-34. DOI: 10.26650/forestist.2019.412545

Karlığlu, N., Akkemik Ü., Caner, H. (2009). Detection of some woody plants in Late Oligocene forests of Istanbul. Turkish Journal of Agriculture and Foresty, 33, 577-584.

Kasapligil, B. (1971). A late Tertiary conifer-hardwood forest from the vicinity of Güvem village, near Kizilcahaman, Ankara. Bulletin of the Mineral Research and Exploration, 88, 94-102.

Kayacık, H., Aytuğ, B., Yaltırık, F., Şanlı, İ., Efe, A., Akkemik, Ü., İnan, M. (1995). Tersiyer'in sonunda İstanbul'un çok yakınında yaşamış Mamut Ağaçları. İstanbul Üniversitesi Orman Fakültesi Dergisi, 1, 15-22.

Kayseri, M. S., Akgün, F. (2007). Palynostratigraphic, palaeovegetational and palaeoclimatic investigations on the Miocene deposits in Central Anatolia (Corum Region and Sivas Basin). Turkish Journal of Earth Sciences, 17, 361-403.

MTA Yerbilimleri Harita Görüntüleyici ve Çizim Editörü, http://yerbilimleri.mta.gov.tr/anasayfa.aspx, 08.09.2018)

Minareci, F. (2005). Karaağaç (Gediz-Kütahya), Baklan (Banaz-Uşak)Çevresindeki (Murat Dă̆ı Masifi) Ofiyolit, Granit Ve Volkanizmayla İlişkili Bazı Cevherleşmelerin Mineralojik İncelenmesi. Dokuz Eylül Üniversitesi, Fen Bilimleri Enstitüsü, Yayınlanmamış Doktora Tezi, İzmir.

Özgüven, K. (1971). Sur un boisfossile de Taxodiaceae dans la flöre Neogened'Istanbul (Turquied'Europe): Sequoioxylon egemenin.sp.. Revue de la Faculté des Sciences de l'Universitéd' Istanbul, 36, 89-114.

Özgüven-Ertan, K. (1977). La stucture D'une Cupressaceae fossile appartenant au Miocene Trouvee dans la region D'egee en Turquie: Cupressinoxylon akdiki n.sp.. İstanbul Üniversitesi Fen Fakültesi Mecmuası, 42 (B1-2), 1-15.

Özgüven-Ertan, K. (1981-1983). Sequoioxylon gypsaceum (Göeppert) Greguss bois fossile du Tertiaire D’Ankara -Beypazarı (Turquie). Istanbul Üniversitesi Fen Fakültesi Mecmuası, 46 (B), 21-28.

Öztürk, A. ve Karadă̆, M. M. (2009). Yukarıkaracahisar (Banaz-Uşak) bölgesinin stratigrafisi ve petrografik özellikleri. Süleyman Demirel Üniversitesi Mühendislik-Mimarlık Fakültesi Dergisi, 4 (24), 1-23.

Sakınç, M., Yaltırak, C., Aras, A. (2007). İstanbul ve Trakya'da silisleşmiş ağaçlar. İstanbul'un Jeolojisi Sempozyumu III 7-9 Aralık 2007, İstanbul.

Şanl1, İ. (1982). Recherches xylologiques sur la flore du Tertiaire de la Thrace Turque. İstanbul Univ. Orman Fak. Derg., 32, $84-138$.

Sayadi, S. (1973). Contribution a l'etude de la floremiocene de la Turquie. Univ. Paris VI.:These.

Selmeier, A., 1990. Dichrostachyoxlon zirkelii (Felix), Mimosoideae, a silicified wood from Miocene sediments of Küçük Çekmece Lake (Turkey). Mitteilungen der Bayerischen Staatssammlung für Paläontologie und Historische Geologie, $30,121-135$.

Semenderoğlu, A., Aytaç, A. S. (2005). Murat Dağı'nın Vejetasyon Coğrafyası. Ulusal Coğrafya Kongresi 2005 (Prof. Dr. İsmail Yalçınlar anısına), 29-30 Eylül 2005, İstanbul.

Türkoğlu, N., Gürgen, G. ve Çiçek, İ. (2009). Çamlıdere fosil ormanının doğal ortam koşulları ve jeomiras bakımından önemi. e-Journal of New World Sciences Academy, 4 (3), 147-156.

Velitzelos, D., Bouchal, J. M. and Denk, T. (2014). Review of the Cenozoic floras and vegetation of Greece. Review of Palaeobotany and Palynology, 204, 56-117. https://doi.org/10.1016/j.revpalbo.2014.02.006 
Wilson, S.McG. Mason, B. Jinks, R. Gil-Moreno, D., Savill, P. (2016). Coast redwood (Sequoia sempervirens), giant redwood (Sequoiadendron giganteum) and western red cedar (Thuja plicata) - species, silviculture and utilisation potential. Quarterly Journal of Forestry, 110 (4), 224-256.

Yalçınlar, İ. (1947). Yukarı Gediz vadisinde Miosene'e ait vertebre fosilleri. Türkiye Jeoloji Bülteni, 1, 164-177.

Yüksel, A. K., Güngör, T., Kılıç, M. A. (2014). Kuzeybatı Anadolu'daki ofiyolit tabanı metamorfik kayaçlarından yeni bulgular (Gediz-Kütahya). Türkiye Jeoloji Bülteni, 2 (57), 19-34.

Yurtseven, N. (2018). Osmancalı (Manisa) köyünde taşlaşmış ormanlar üzerine coğrafi inceleme. TÜCAUM 30. Yıl Uluslararası Coğrafya Sempozyumu, 3-6 Ekim 2018, 875-892, Ankara 